\title{
ZnO(101) films by pulsed reactive crossed-beam laser ablation
}

\author{
S ANGAPPANE ${ }^{1,2}$, N R SELVI ${ }^{1}$ and G U KULKARNI ${ }^{1, *}$ \\ ${ }^{1}$ Chemistry and Physics of Materials Unit and DST Unit on Nanoscience, \\ Jawaharlal Nehru Centre for Advanced Scientific Research, Jakkur P.O., Bangalore 560 064, India \\ ${ }^{2}$ Centre for Liquid Crystal Research, Jalahalli, Bangalore 560 013, India
}

\begin{abstract}
We have employed pulsed reactive crossed-beam laser ablation (PRCLA) to deposit a (101) oriented $\mathrm{ZnO}$ film. In this method, a supersonic jet of oxygen pulse is made to cross the laser plume from a zinc metal target while being carried to the $\mathrm{Si}(111)$ substrate. The obtained deposit was nanocrystalline $\mathrm{ZnO}$ as confirmed by a host of characterization techniques. When the substrate was held at varying temperatures, from room temperature to $900^{\circ} \mathrm{C}$, the crystallinity of the obtained films increased as expected, but importantly, the crystallographic orientation of the films was varied. High substrate temperatures produced the usual (001) oriented films, while lower substrate temperatures gave rise to increasingly (101) oriented films. The substrate held at room temperature contained only the (101) orientation. The film morphology also varied with the substrate temperature, from being nanoparticulate to rod-like deposits for higher deposition temperatures. Surprisingly, the (101) orientation showed reactivity with acetone forming carbonaceous nanostructures on the surface.
\end{abstract}

Keywords. ZnO films; $\mathrm{ZnO}(101)$; pulsed laser deposition; reactive laser ablation; surface reactivity; carbon nanostructures.

\section{Introduction}

With its wide direct bandgap $(\sim 3.37 \mathrm{eV})$ and high exciton binding energy $(\sim 60 \mathrm{meV})$, zinc oxide is known to be one of the most promising oxide semiconductors with applications in light-emitting devices, window materials in solar cells, display devices, high-temperature and highpower transistors and gas sensing (Özgür et al 2005; Jagadish and Pearton 2006; Klingshirn 2007; Rout et al 2007). In recent years, various forms of $\mathrm{ZnO}$, such as thin films, nanorods, nanowires, nanobelts, nanorings, nanocages, etc have been prepared by physical and chemical routes aiming at various applications (Heo et al 2004; Rao et al 2007). Diverse methods have been applied to synthesize $\mathrm{ZnO}$ nanostructures including solvothermal synthesis (Biswas et al 2008), chemical vapour deposition (Wang 2004), hydrothermal synthesis (Choy et al 2004), template-assisted routes (Liu et al 2003) and pulsed laser deposition (PLD) (Nobis et al 2004; Sun et al 2004; Angappane et al 2006).

Among the physical routes, pulsed laser deposition (PLD) has several advantages over the other methods. Mainly, it is versatile with the merit that it faithfully transfers the target composition to the deposited material, particularly important in doping experiments (Chrisey and Hubler 1994). Using PLD, aligned growth of $\mathrm{ZnO}$

\footnotetext{
*Author for correspondence (kulkarni@jncasr.ac.in)
}

nanowires and nanorods on Si substrates has been demonstrated (Nobis et al 2004; Sun et al 2004). We have synthesized $\mathrm{ZnO}$ pyramidal nanostructures on $\mathrm{Si}(100)$ substrate using PLD (Angappane et al 2006). The presence of droplet particulates on the film, incongruent ablation and possible oxygen deficiency in the produced films are found to be limitations of the PLD (Chen 1994). With the aim of overcoming these limitations, several modifications have been suggested for conventional PLD; off-axis PLD, magnetic-field assisted PLD, PLD with an electric field applied to the substrate, RF plasma and UV assisted PLD and pulsed reactive crossed-beam laser ablation (PRCLA) to name a few (Willmott and Huber 2000; Willmott 2004). PRCLA was first introduced by Gupta and Hussey (1991) who used pulsed high intensity jet of oxygen to make films of high- $T_{\mathrm{C}}$ superconductors by PLD. The gas pulse emerging from a nozzle valve was made to impinge at a point on the target where the laser was focused. As the plasma expands and propagates through the gas pulse, which is a transient high pressure region, it transfers some of its energy to the gas particles via collision. The gas pulse not only creates a high pressure reaction but also carries the plume and product species along towards the substrate kept parallel to the valve nozzle. PRCLA has been successfully used to reduce and deflect particulates from the deposition plume (Schenck et al 1998). PRCLA has also been applied to fabricate preferentially oriented films. Montenegro et al (2004) employed PRCLA to define the orientation of $\mathrm{La}_{0.6}$ $\mathrm{Ca}_{0.4} \mathrm{CoO}_{3}$ thin films. 
In this article, we report our investigations on $\mathrm{ZnO}$ films deposited on $\mathrm{Si}(111)$ substrates employing PRCLA. The depositions were carried out in oxygen pulse with the substrate held at different temperatures. The obtained films have been examined employing a host of characterization techniques, XRD, SEM and TEM as well as by electrical resistivity measurements. A preliminary study has also been carried out to find out reactivity of the films. Our study has shown that depending on the substrate temperature employed during deposition, the films exhibit preferred orientations which in turn influence their reactivity pattern.

\section{Experimental}

Frequency tripled pulsed Nd: YAG laser (Quanta-Ray GCR-170, Spectra-Physics, USA) with a pulse width of $\sim 5 \mathrm{~ns}$ and repetition rate of $10 \mathrm{~Hz}$ was employed for the ablation of zinc target (Johnson Matthey Co. UK, 99.99\%). Pulsed supersonic valve (R.M. Jordan, USA) was placed perpendicular to the laser beam and at $45^{\circ}$ to the plume. The Si(111) substrate was held opposite to the pulse valve at $\sim 5 \mathrm{~cm}$. Prior to mounting, the $\mathrm{Si}(111)$ substrate was cleaned using the piranha solution $\left(1: 2 \mathrm{H}_{2} \mathrm{O}_{2}: \mathrm{H}_{2} \mathrm{O}\right)$ (Caution: this mixture reacts violently with organic matter) and etched in $\mathrm{HF}\left(1: 10 \mathrm{HF}: \mathrm{H}_{2} \mathrm{O}\right)$ to remove residual $\mathrm{SiO}_{x}$ layer. In order to make maximum interaction of the gas pulse with plume, the distance between the pulse valve tip and the interacting point of the laser beam was optimized to less than or equal to $10 \mathrm{~mm}$ (Willmott and Huber 2000). Supersonic oxygen gas pulse was introduced into the chamber for $100 \mu \mathrm{s}$; the laser lamp was excited with $10 \mu \mathrm{s}$ pulse with $400 \mu \mathrm{s}$ delay and consequently Q-switch was excited with a $10 \mu$ s pulse delayed by $580 \mu \mathrm{s}$ with respect to the pulse valve using a pulse generator (Model 9650A, EG\&G, USA). These time delays were optimized for the maximum yield of the deposition onto the substrate. The pressure of the oxygen supply to the pulsed supersonic valve was kept at about 7 bar. The deposition was made at different substrate temperatures, viz. room temperature $\left(\sim 25^{\circ} \mathrm{C}\right), 400,600,750$ and $900^{\circ} \mathrm{C}$ for $45 \mathrm{~min}$.

The X-ray diffraction measurements were carried out on the grown films using a Miniflex (Rigaku, Japan) $\left(\mathrm{CuK}_{\alpha}\right.$, $1.5406 \AA$; scan rate, $1 \mathrm{deg} / \mathrm{min}) \mathrm{X}$-ray diffractometer. Scanning electron microscopy (SEM) of the films were carried out using Leica model S-440I equipment, whereas field emission scanning electron microscopy (FESEM) images were taken using the Nova NanoSEM 600 instrument (FEI Co., The Netherlands), equipped with energy dispersive X-ray (EDX) analysis (EDAX, AMETEK Inc., USA) employed for determining the surface composition of our films. Atomic force microscopy (AFM) measurements were done using a Multimode ${ }^{\mathrm{TM}}$ Scanning Force Microscope attached to Nanoscope IV Controller (Digital
Instruments, USA). Transmission electron microscopy (TEM) was carried out using a JEOL 3010 operating at $300 \mathrm{kV}$ on a part of the film scratched and placed on a TEM grid.

\section{Results and discussion}

XRD patterns of the $\mathrm{ZnO}$ films deposited on $\mathrm{Si}(111)$ substrates are shown in figure 1 . The film deposited with the substrate held at room temperature $\left(25^{\circ} \mathrm{C}\right)$ exhibits a single peak at $2 \theta$ of $36.36^{\circ}$, which translates to a $d$-spacing of $2.4679 \AA$. This spacing corresponds to the (101) plane of $\mathrm{ZnO}$ (JCPDS \#36-1451). Given that the preferred growth for $\mathrm{ZnO}$ is along the [001] direction on various substrates
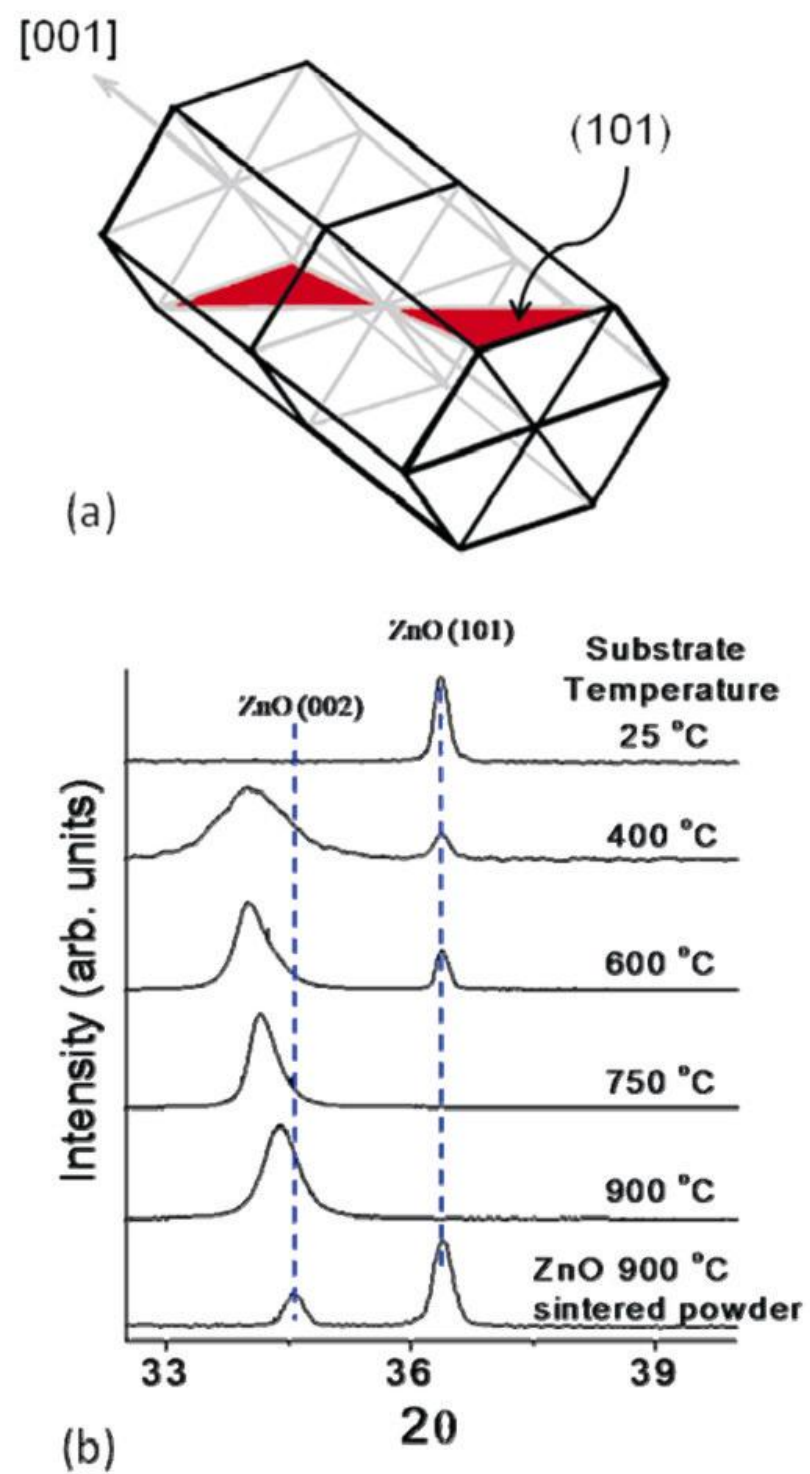

Figure 1. (a) $\mathrm{ZnO}$ unit cell showing the (101) plane and (b) $\mathrm{XRD}$ pattern of $\mathrm{ZnO}$ prepared by pulsed reactive crossed-beam laser ablation at various substrate temperatures. The data from a sintered powdered sample is also shown. 
(Shi et al 2002; Kang et al 2004; Teng et al 2006), the observation is unusual. It may be noted that the (101) plane is a high density crystal plane (see the unit cell in figure 1a) showing maximum diffraction intensity in the bulk powder pattern, such as from a sintered sample also shown in figure $1 \mathrm{~b}$. When the substrate temperature was increased to $400^{\circ} \mathrm{C}$, the $\mathrm{XRD}$ data shows the presence of a broad peak centred at $34.06^{\circ}$ along with the $\mathrm{ZnO}(101)$ peak of diminished intensity. The former is assignable to the (002) peak of $\mathrm{ZnO}$, albeit its shift $\left(34.06^{\circ}\right.$ as against $34 \cdot 22^{\circ}$ ). The shift and the broad nature of the peak together indicate that the $\mathrm{ZnO}$ species grown is in the form of nanoparticles which may be defective. For a substrate temperature of $600^{\circ} \mathrm{C}$, the $(002)$ peak becomes narrower and is shifted to higher angles, retaining the (101) peak. Interestingly, the XRD patterns obtained with the substrate deposition temperatures of $750^{\circ} \mathrm{C}$ and $900^{\circ} \mathrm{C}$ exhibit sharper (002) peaks at progressively higher angles, the (101) reflection being completely absent. Undoubtedly, these films possess increased crystallinity oriented along the $c$-axis. In another study, highly $c$-axis oriented $\mathrm{ZnO}$ films have been produced with the substrate being held at $400^{\circ} \mathrm{C}$ (Zhao et al 2006). It appears that under the reactive conditions adopted in our experiments, the $\mathrm{ZnO}$ cluster species tend to grow along the maximum density (101) plane especially when the substrate temperature is low enough not to induce annealing. An increase of the substrate temperature improves the mobility of the deposited atoms and enhances the preferred (001) directional growth of film. Previously, Fan et al (2005) achieved the (101) orientation by using a high laser energy density. It appears that in this case, the plasma itself carried some internal stress which induced a preferential growth. A theoretical study (Park and Park 1999) has shown that the presence of stress can alter the energetic balance between the (002) and (101) orientations.

Figure 2 shows the AFM images of the deposited films. The nanoparticulate morphology is evident in all the cases. The size of the particulate increases from $50 \mathrm{~nm}$ at $25^{\circ} \mathrm{C}$ to 90 and $100 \mathrm{~nm}$ with increasing substrate temperatures of 600 and $750^{\circ} \mathrm{C}$, respectively. The films are generally smooth. The roughness as determined from the AFM analysis varies with the substrate temperature employed during deposition, 1.9, 3.8 and 4.2 $\mathrm{nm}$ for the 25,600 and $750^{\circ} \mathrm{C}$ films, respectively. When the substrate temperature is increased to $900^{\circ} \mathrm{C}$ during PRCLA (figure 3), the deposition is less but well defined nanostructures seem to emerge as shown in the SEM image in figure 3a. Many rod-like features with sharp boundaries are seen all over the surface. The bright-field TEM image of one such rod is shown in figure $3 \mathrm{~b}$. Its lateral dimension is $\sim 70 \mathrm{~nm}$ and length, $\sim 100 \mathrm{~nm}$. The HRTEM image in figure $3 \mathrm{c}$ shows the lattice fringes with a spacing of $2.6 \AA$ from the (002) planes, indicating that the $\mathrm{ZnO}$ nanostructures grow along the [001] crystallographic direction. Electron diffraction pattern taken on the hexagonal structures indicate
[001] zone axis of $\mathrm{ZnO}$ crystal, consistent with the XRD result.
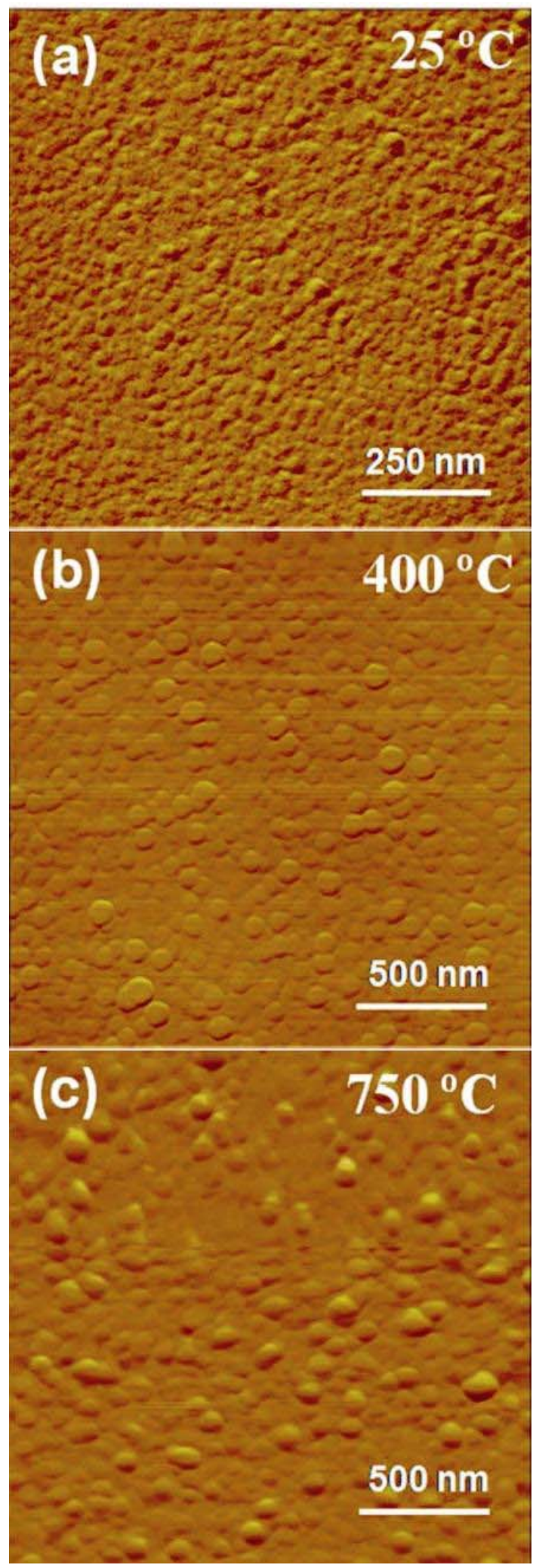

Figure 2. AFM images of the $\mathrm{ZnO}$ films deposited at (a) 25, (b) 400 and (c) $750^{\circ} \mathrm{C}$ showing surface features; the grain size is found to increase with the substrate temperature 
The surface resistivity of the films measured by the four-probe method showed a value of $0 \cdot 1 \Omega$-cm for the
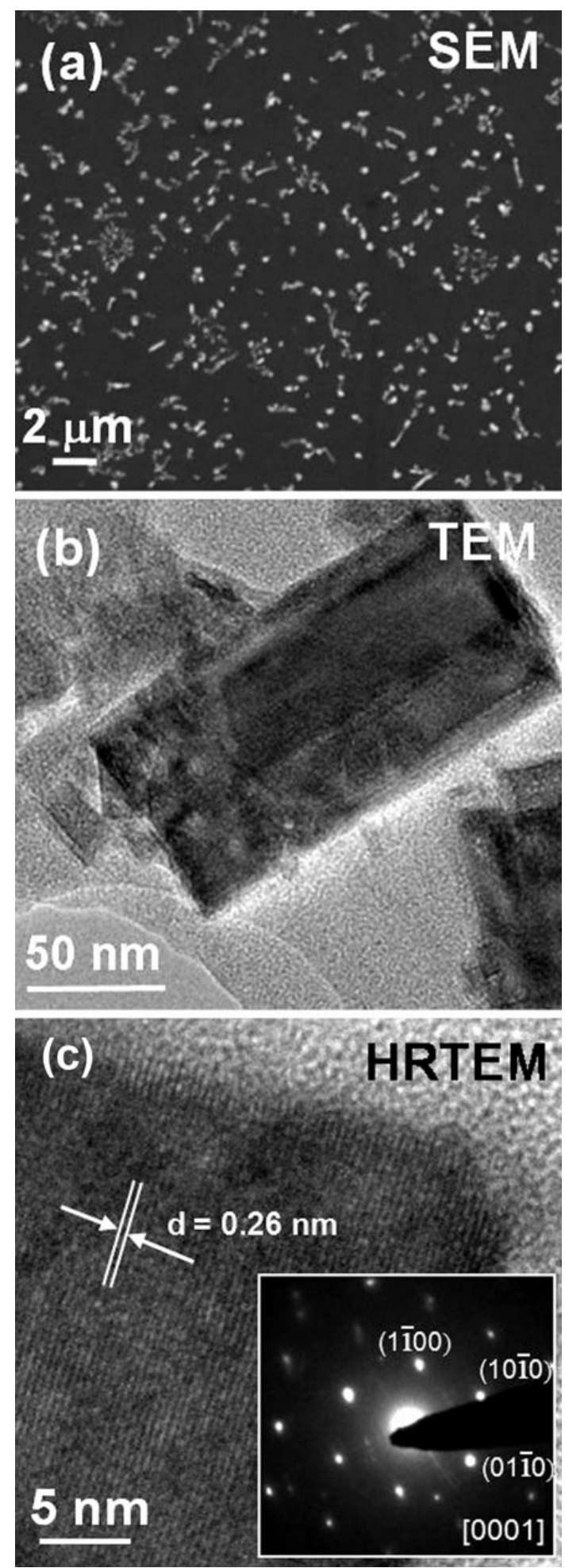

Figure 3. $\mathrm{ZnO}$ film deposited at $900^{\circ} \mathrm{C}$ : (a) SEM image showing nanostructures present on the surface, (b) TEM image of the hexagonal shaped $\mathrm{ZnO}$ nanorods and (c) HRTEM image showing lattice fringes of $c$-axis oriented $\mathrm{ZnO}$. Inset shows the electron diffraction pattern of a $\mathrm{ZnO}$ nanorod showing $c$-axis [001] oriented growth. $25^{\circ} \mathrm{C}$ film which increased exponentially to $51.4 \Omega-\mathrm{cm}$ for the film deposited at $900^{\circ} \mathrm{C}$ (figure 4). Such an increase in the resistivity at high deposition temperatures may be due to a reduction in the number of defect electronic states (Zeng et al 2002). However, these values are much lower compared to the bulk $\mathrm{ZnO}$ resistivity of $380 \Omega-\mathrm{cm}$ (Maeda et al 2005). As the deposited films are found to contain excess oxygen (EDX value, $\mathrm{Zn}: \mathrm{O}=1: 1 \cdot 7$ ), the resistance values are lower compared to the crystalline bulk. Higher the substrate temperature, lesser would be the density of defect electronic states which explains the increase in electrical resistivity.

We have found the $\mathrm{ZnO}(101)$ surfaces prepared by us to be reactive towards organic solvents such as acetone. When dipped in acetone for a few minutes, the surface was seen covered with nanostructures as shown in the SEM and AFM images in figures 5 and 6. The EDS analysis of the surface (also shown in figures 5 and 6) indicated that the new nanostructures contained predominantly carbon in some form. Such rod-like carbonaceous deposits occurred more on the surface of the $25^{\circ} \mathrm{C}$ film. The $400^{\circ} \mathrm{C}$ film also contained these nanostructures. AFM analysis showed that the structures are $50-200 \mathrm{~nm}$ in height and few tens of nanometers to few micrometers in length. Thus, the reactive nature of the $\mathrm{ZnO}(101)$ surfaces is evident. The carbon deposits are found much less on the $750^{\circ} \mathrm{C}$ film (figure 6), which was also subjected to acetone treatment. The structures were completely absent in the case of the $900^{\circ} \mathrm{C}$ film. The absence of carbonaceous deposits on the crystalline $\mathrm{ZnO}(001)$ surface demonstrates that the catalytic activity is unique to $\mathrm{ZnO}(101)$ surface which has not been reported earlier. However, the origin of such activity is unclear at present. Further studies on $\mathrm{ZnO}(101)$ surface are in progress using surface techniques.

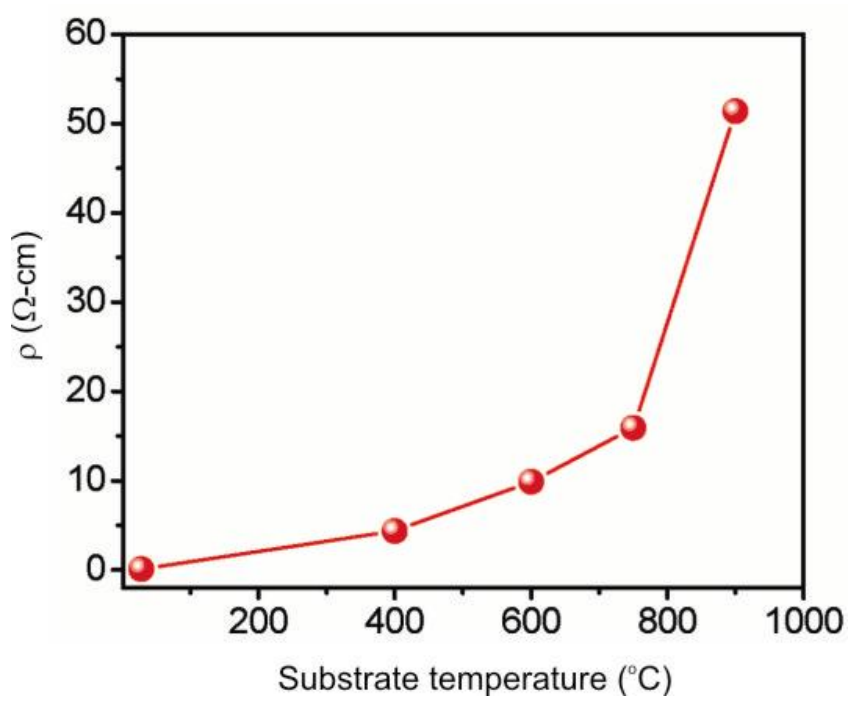

Figure 4. Surface resistivity of $\mathrm{ZnO}$ films deposited at different substrate temperatures. 


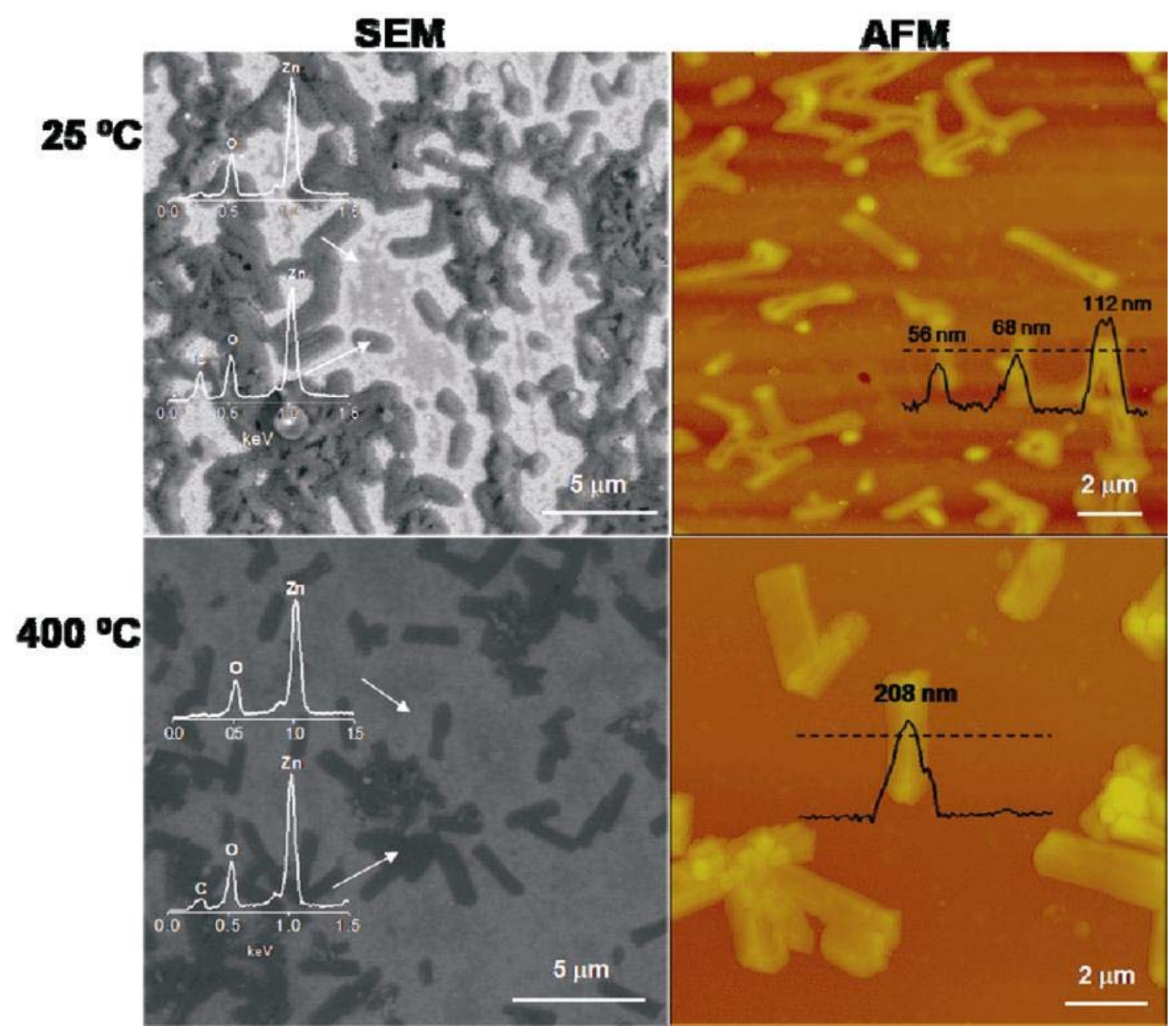

Figure 5. SEM and AFM images of the surfaces of $\mathrm{ZnO}$ films after being treated with acetone; bunches of carbon nanostructures are found on the surface. Insets show the EDX analysis of the surface chemical species and the AFM images are height profiles of the surface nanostructures.

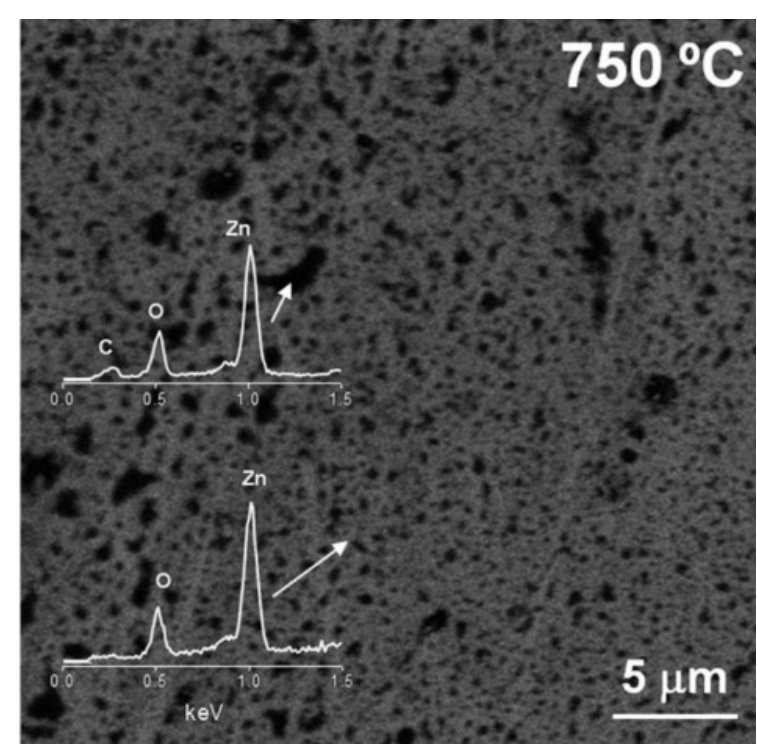

Figure 6. SEM image of the acetone treated surface of $\mathrm{ZnO}$ film deposited at $750^{\circ} \mathrm{C}$ showing very few carbon nanostructures. Insets show the EDX analysis of the surface chemical species.

\section{Conclusions}

We have successfully produced entirely (101) oriented $\mathrm{ZnO}$ films on $\mathrm{Si}(111)$ substrates employing pulsed reactive crossed-beam laser ablation. The favourable conditions for this process are laser plume from a $\mathrm{Zn}$ metal target carried to the substrate by an oxygen pulse, with the substrate being held at room temperature. The obtained film contained tightly packed nanoparticulates in the size range, $50-100 \mathrm{~nm}$. With increasing substrate temperatures of 400 and $600^{\circ} \mathrm{C}$, the films were of mixed orientations, (101) and (001), the latter being broad and shifted (with respect to bulk) to lower $\theta$ values due to defect nature of the particulates. At a substrate temperature of $750^{\circ} \mathrm{C}$, the intensity of the (101) peak diminished with (001) becoming sharper indicating increasing crystallinity. At $900^{\circ} \mathrm{C}$, the substrate produced a film entirely with the (001) orientation with larger hexagonal shaped particulates $(\sim 70-100 \mathrm{~nm})$. Interestingly, the (101) oriented film showed high reactivity with acetone producing rod-like carbonaceous deposits, typically tens of nanometer high and few micrometer in length distributed all over 
the film. The $(001)$ orientation was found to be less reactive. Further studies are underway to explore $\mathrm{ZnO}(101)$ surfaces as an effective catalyst for controlled growth of carbon nanostructures.

\section{Acknowledgements}

The authors are grateful to Prof. C N R Rao for his support and encouragement. The financial support from the Department of Science and Technology (DST), Government of India, is gratefully acknowledged.

\section{References}

Angappane S, John N S and Kulkarni G U 2006 J. Nanosci. Nanotech. 6101

Biswas K, Das B and Rao C N R 2008 J. Phys. Chem. C112 2404

Chen L C 1994 Particulates generated by pulsed laser ablation, in Pulsed laser deposition of thin films (eds) D B Chrisey and G K Hubler (New York: Wiley) p. 167

Choy J H, Jang E S, Won J H, Chung J H, Jang D J and Kim Y W 2004 Appl. Phys. Lett. 84287

Chrisey D B and Hubler G K (eds) 1994 Pulsed laser deposition of thin films (John Wiley \& Sons)

Fan X M, Lian J S, Guo Z X and Lu H J 2005 J. Cryst. Growth 279447

Gupta A and Hussey B W 1991 Appl. Phys. Lett. 581211

Heo Y W, Norton D P, Tien L C, Kwon Y, Kang B S, Ren F, Pearton S J and LaRoche J 2004 Mater. Sci. Engg. R47 1

Jagadish C and Pearton S J (eds) 2006 Zinc oxide-Bulk, thin films and nanostructures (Amsterdam: Elsevier)
Kang H S, Kang J S, Kim J W and Lee S Y 2004 Phys. Status Solidi (c) 12550

Klingshirn C 2007 Phys. Status Solidi (b) 2443027

Liu C, Zapien J A, Yao Y, Meng X, Lee C S, Fan S, Lifshitz Y and Lee S T 2003 Adv. Mater. 15838

Maeda K, Sato M, Niikura I and Fukuda T 2005 Semicond. Sci. Technol. $20 \mathrm{~S} 49$

Montenegro M J, Lippert T, Müller S, Weidenkaff A and Wokaun A 2004 Handai nanophotonics (eds) H Masuhara and S Kawata 1 p. 251

Nobis T, Kaikashev E M, Rahm A, Lorenz M, Lenzner J and Grundamann M 2004 Nanolett. 4797

Özgür Ü, Alivov Ya I, Liu C, Teke A, Reshchikov M A, Doğan S, Avrutin V, Cho S-J and Morkoç H 2005 J. Appl. Phys. 98 041301

Park K S and Park J K 1999 Acta Mater. 472177

Rao C N R, Thomas P J and Kulkarni G U 2007 Nanocrystals: synthesis, properties and applications Springer Series in Materials Science Vol. 95

Rout C S, Kulkarni G U and Rao C N R 2007 J. Phys. D: Appl. Phys. 402777

Schenck P K, Vaudin M D, Bonnell D W, Hastie J W and Paul A J 1998 Appl. Surf. Sci. 127-129655

Shi W S, Agyeman O and Xu C N 2002 J. Appl. Phys. 915640

Sun Y, Fuge G M and Ashfold M N R 2004 Chem. Phys. Lett. 39621

Teng X M, Fan H T, Pan S S, Ye C and Li G H 2006 J. Phys. D: Appl. Phys. 39471

Wang Z L 2004 Mater. Today 726

Willmott P R and Huber J R 2000 Rev. Mod. Phys. 72315

Willmott P R 2004 Prog. Surf. Sci. 76163

Zeng J N, Low J K, Ren Z M, Liew T and Lu Y F 2002 Appl. Surf. Sci. 197-198 362

Zhao J, Hu L, Wang Z, Sun J and Wang Z 2006 Appl. Surf. Sci. 253841 